\title{
Self-report prospective memory problems in people with stroke
}

\begin{abstract}
Background and Purpose: Prospective memory (PM) is a common problem which can limit performance of basic and instrumental activities of daily living in stroke patients. We compared self-report PM failures between older and younger people with stroke, examined differences in perceptions of PM failures between people with stroke and relatives, relationships between these PM failures and functional performance.
\end{abstract}

Methods: A total of 105 stroke patients, 65 relatives and 112 healthy controls were recruited. Both the stroke patients and controls were further divided into an older (age $>55$ years) and a younger (age $\leq 55$ years) group. Data for stroke patients and relatives were obtained via the Brief Assessment of Prospective Memory (BAPM), Basic Activity of Daily Living (BADL) related Modified Barthel Index (MBI) and Lawton Instrumental Activities of Daily Living (Lawton IADL) Scale. Healthy controls' data were also collected.

Results: The older stroke group had significantly higher BAPM total scores and BADL and IADL subscale scores than the younger group. Difference in perceptions of the patients' self-report of PM failures and their relatives' report was significant for the IADL subscale. Self-report of PM failure was significantly related to functional BADL and IADL measures.

Conclusions: Results highlight the impact of PM failures in stroke patients and their assessment, management, and rehabilitation of these patients.

Key Words: prospective memory, stroke, functional, age, ADL, IADL 


\section{Introduction}

According to a recent World Health Organization Global burden report [1], stroke was one of the main causes of death and disability in the world. 15 million people worldwide suffer a stroke 2014. Of these, 5 million died and another 5 millons are left permanently disabled, placing a burden in family and community. Incidence of stroke has been associated with older age and about $75 \%$ of stroke occurs over the age of 65 years $[2,3]$. Nowadays, significant numbers of people suffer strokes at a younger age $[4,5]$. About $12 \%$ of stroke patients report their first stroke between 18 and 50 years [6]. The incidence of stroke in young people in both North America and Western European countries in the 1980 s was about $4 \%$ [7, 8]. More recently $25 \%$ of stroke patients in the UK were young people [9] and it was estimated that 2 million young people suffer a stroke every year in the world [10]. However, the definition of young stroke can be different from one study to another. Some studies considered persons with stroke who were aged between 18 and 65 years as younger stroke survivors $[9,11]$. Other studies defined younger stroke patients as patients up to 45 years or 55 years of age [12]. In the present study, the age range of 'younger stroke' patients was operationally defined as between 18 to 55 years old and those over 55 years were considered older stroke patients, as there is an increase in life expectancy and more and more people are retiring late.

As a medical emergency, stroke can cause permanent neurological damage, complications, adult disability, and death [13]. Permanent neurological damage may affect many aspects of functioning including attention, memory, reasoning, perception, vision and motor control [14]. Memory deficits, including prospective memory (PM) impairment [15], can be one of the most obstructive factors that influence the two types of daily living activities: performance of basic (BADL) and instrumental activities of daily living (IADL) [16]. BADL refers to basic daily routine including self-care activities such as bathing, dressing, feeding and using the toilet. IADL 
refers to more complex task such as using the telephone, preparing meals, shopping and using public transport. PM refers to the ability to "remember to perform an intended action at a particular point in the future" [17]. It can be divided into three sub-types, namely, time-based, event-based and activity-based [18]. All three types of PM require the execution of an intended action in a delayed situation while performing an on-going task at the same time. For time-based PM, the intended action should be performed at a specific time, such as an appointment at 10 a.m. For event-based PM, the intended action should be performed when a particular cue appears (e.g., call the manager when an invited customer arrives at the office). Finally, activity-based PM is similar to event-based PM in that both require a person to carry out an intended action when a cue appears. However, the former it does not involve the interruption of the on-going task. An everyday example of activity-based PM task is switching off the computer when one finishes checking all the e-mails. Most PM researchers contrast PM with retrospective memory (RM). According to Cockburn [19], RM and PM are similar in that memory for content is essential to both. However the essential differences between these two memory constructs are: (1) remembering prospectively also requires memory for intention, and (2) the cue for retrieval has to be self-initiated in PM but not in RM. Similarly, Einstein and McDaniel [20] suggested that while someone (e.g., an experimenter or a teacher) initiates or requests the act of remember in RM, PM requires a person to remember to remember in the first place. PM has a major impact on individuals' quality of life as well as ADL. Impairment of PM can make rehabilitation more difficult. Patients might not be able to follow through steps towards any organized meaningful activity or remember to initiate strategies or practice activities outside of therapy sessions. Assessment and intervention of a patient's PM impairment should therefore be an important focus of any cognitive rehabilitation program. 
Research in the schizophrenia area has shown that better performance on PM tests predicts higher functional capacity as measured by a standardized activity of daily living (ADL) scale [21]. Given the significant effects a stroke can have on the brain, it is logical to assume that stroke patients would have PM problems [22-24]. In addition, given the effect of ageing on both RM and PM, younger and older stroke patients are expected to show different levels of PM impairment [25]. To date, however, few studies have compared the performance between young and old stroke patients as well as with healthy control groups to investigate whether they showed significant differences on different types of PM tasks. Thus, the aims of the current study were to explore whether there was a difference in frequency of PM failure between two stroke patient groups (younger and older) and their corresponding age-similar healthy control groups in their self-report PM, and to explore the differences between stroke patients' self-report of PM failure and their relatives' reports. Finally, we aimed to examine the relationships between PM failure and functional BADL and IADL performance in the two stroke groups as a whole.

\section{Method}

\section{Study design and participants}

This study used a cross-sectional survey design and a mailed questionnaire to examine stroke patients' self-report PM failures and their functional abilities. Similar questionnaires were sent to their relatives or main caregivers to fill in. The stroke and family participants were recruited from local hospitals, rehabilitation centers, day hospitals, outpatient clinics and self-help groups in Hong Kong. While the younger healthy controls were recruited from The Hong Kong Polytechnic University, the older controls were recruited through three local elderly services centers run by a large NGO called The Neighbourhood Advice-Action Council (NAAC). The convenience 
sampling method was used in this study for selecting both stroke patients and health control. The inclusion criteria for stroke patients were: (a) age 18 years or above; (b) either gender; (c) a diagnosis of suffering from a stroke as confirmed by a CT or MRI scan and had a post stroke period over 6 months; (d) willingness to participate. The exclusion criteria were: (a) being diagnosed with other neurological conditions such as Parkinson's disease, traumatic brain injury, epilepsy etc.; (b) having a recurrent stroke; (c) alcoholism; (e) associated psychiatric and behavioural symptoms; (f) dementia or mild cognitive impairment (MCI)

\section{Instrumentation}

A similar 4-part questionnaire was put together for both stroke patients and their relatives. The first part covered personal demographics including age, gender, marital status, educational level and types of hemiplegia. For relatives, the relationship with the patients was also recorded.

The second part was a validated Brief Assessment of Prospective Memory (BAPM) [26]. This self-report instrument consists of 16 questions which are related to PM in both basic activities of daily living (8-item BAPM-BADL) and instrumental activities of daily living (8-item BAPM-IADL). Previously it has been used for evaluation of PM performance in people with traumatic brain injury. Frequency of PM failure in the last month is self-rated on a five-point scale where $1=$ 'never' and $5=$ 'very often'. Items can also be scored as 'not-applicable'. Mean scores for the BADL and IADL subscales and total scores are calculated by adding item responses together and then dividing by the total number of items rated, with not applicable responses excluded from the mean scores. Subscale scores can therefore range from 1 to 5 with higher scores indicating more frequent PM failure. 
The last two parts of the questionnaire aimed to assess the functional level of patients and included the Modified Barthel Index or MBI [27] for evaluating the patients' BADL and the Hong Kong Lawton IADL Scale $[28,29]$ for assessing IADL. The former is a 10 -item index which is targeted at measuring the degree of independence of a patient, covering areas such as feeding, transfer, grooming and toilet use and has a score range of 0-20 [30]. The latter scale, developed by Lawton, defines IADL as complex activities vital to maintaining independent living in the community. In the present study, the Hong Kong version was used and it consists of a total of nine items (including the use of telephone, transportation, shopping, medication management, money management, meal preparation, housework, and laundry work) with scores ranging from 0-27. For healthy controls, a shorter questionnaire consisting of basic personal information and was used, instead of the full version used with the stroke patients and their relatives.

\section{Procedures}

Ethical clearance was obtained from the Research Ethics Committee of participating centers, hospitals under Hospital Authority and The Departmental Research Committee of Rehabilitation Sciences, The Hong Kong Polytechnic University respectively. Patients with stroke who met the selection criteria were invited to participate in the study. Firstly, the researchers sent the consent forms and questionnaires to the recruiting centers and hospitals. Secondly, written consent from participant was obtained by therapists or center staff, and returned within one week. The questionnaires together with return-mail envelopes were then sent to consenting participants by mail and they were asked to return the completed package within 2 weeks. A reminder was sent after the deadline of reply. Students recruited as younger healthy controls from the Hong Kong Polytechnic University were invited to complete the questionnaire on campus. The elderly 
participants were recruited through the NAAC and they were assisted to fill in the questionnaire by center staff.

\section{Statistical Analysis}

Data were analyzed using IBM SPSS Statistics for Windows (Version 20.0) [31]. Descriptive statistics were obtained for basic demographic data such age, gender, education level, types of hemiplegia, post stroke period, history of illness. Independent samples t-tests or Chi-square tests were used to test for homogeneity of the stroke and corresponding age-similar groups in their demographics such as age and gender. Comparisons of BAPM scores (BADL, IADL, TOTAL) between stroke groups (the younger and older stroke groups); between stroke and the age-similar healthy control groups, and between stroke patients and their relatives who also responded to questionnaire study. The analyses were conducted using one-way Analysis of Variance and posthoc test using Tukey's test. Associations between BAPM scores and functional BADL and IADL were examined using Pearson's correlation coefficients.

\section{Results}

\section{Demographic data}

Table 1 shows the demographics of the stroke and healthy control groups. A total of 217 participants were successfully recruited. There were 105 stroke patients and $65(62 \%)$ of their relatives also agreed to take part in the study. Their relationships with patients were respectively spouses $(75.4 \%)$, children $(13.8 \%)$, parents $(4.6 \%)$, siblings $(4.6 \%)$ and others $(1.5 \%)$. Of the stroke group, 29 and 46 were classified according to their age range as the younger and older stroke group respectively. For the 112 healthy controls, there were 46 younger and 66 older adults 
respectively. There were no statistically significant differences in age, gender and educational level respectively between young stroke and control group $\left(\mathrm{t}=1.79, \mathrm{p}=0.07 ; \chi^{2}=0.59, \mathrm{p}=0.44 ; \chi^{2}\right.$ $=3,43, \mathrm{p}=0.33)$; and between older stroke and control group $\left(\mathrm{t}=-1.52, \mathrm{p}=0.13 ; \chi^{2}=0.03, \mathrm{p}=0.86\right.$; $\left.\chi^{2}=7.93, \mathrm{p}=0.16\right)$. The groups were considered to be age-, gender- and education-similar for other comparison purposes.

\section{Insert table 1 about here}

\section{BAPM in younger and older stroke patients and healthy controls}

Table 2 presents the scores of the younger and older groups of stroke patients and the corresponding healthy control groups on the three scores of the BAPM. Except for similar BAPM-BADL scores of the younger $($ mean $=1.14)$ and older control groups $($ mean $=1.11)$, the older groups had higher mean scores (range $=1.11-1.60)$ on the three scales indicating more frequent PM failure, irrespective of whether they were in the stroke (range $=1.22-1.60$ ) or healthy control group (range=1.10-1.39). Similarly, stroke group had higher mean scores than healthy control group of the same age group. For all comparisons, the older stroke group had higher BAPM-BADL, BAPM-IADL, BAPM-TOTAL mean scores (1.49, 1.60, and 1.46 respectively) indicating more frequent PM failure compared to the individual means of the other three groups as well as the means of the three groups combined (1.15, 1.34, 1.18 respectively).

\section{Insert table 2 about here}

According to the results of one-way ANOVA, there were significant differences $(p<0.001)$ in the BAPM-BADL score $(\mathrm{F}=10.57)$, BAPM-IADL score $(\mathrm{F}=7.14)$ and the BAPM-IADL score 
$(\mathrm{F}=8.75)$ in the four groups (stroke-young and old; healthy control -young and old). Post hoc analysis using Tukey's test indicates that, for BAPM-BADL, the only significant difference was between the older stroke group and the younger control group $(p<0.001)$. For BAPM-IADL, the older stroke group reported more frequent PM failure than the younger stroke $(p=0.029)$, younger control $(p<0.001)$ and older control $(p<0.001)$ groups. The BAPM-TOTAL score of the older stroke group was also significantly different from the younger $(p<0.001)$ and older control $(p=0.01)$ groups

\section{Comparison of PM ratings of stroke patients and relatives}

Table 3 compared the patients' score with their relatives for the younger and older stroke patient groups and both groups combined. Relatives' ratings of patients' PM failures on the BAPMBADL scale were not significantly different from the patients' ratings for both the younger and older stroke group $(t=0.66, p=0.55 ; t=0.86, p=0.39$ respectively). A significant difference was found for BAPM-IADL score $(t=2.88, p=0.05)$ for the older stroke group only, but not for the younger stroke group $(t=0.93, p=0.38)$. The difference in BAPM-total score was not significant for both the older $(t=0.84, p=0.42)$ and the younger stroke $(t=2.04, p=0.43)$ groups. When the older and younger stroke groups were combined into one sample there was a significant difference between patient and relatives' ratings for the BAPM-IADL score $(t=2.56, p=0.01)$, with relatives rating the patient's PM failure as more frequent.

Insert table 3 about here 


\section{Correlations between PM, ADL and IADL}

The correlations between BAPM-BADL and functional BADL, BAPM-IADL and functional IADL and total BAPM and total ADL functional assessments in the patient groups and relatives group are shown in table 4 . There were significant negative relationships between BAPM-BADL and MBI scores $(r=-0.40, p<0.01)$, BAPM-IADL and Lawton IADL scores $(r=-0.27, p<0.01)$, as well as BAPM-total and Total ADL $(r=-0.36, p<0.01)$ for the full sample of patients. For the older stroke group, moderate strength of relationship (i.e. value of $r=0.3-0.5$ ) were found between BAPM-IADL and Lawton IADL $\operatorname{scores}(r=-0.24, p<0.05)$, between BAPM-BADL and MBI scores $(r=-0.48, p<0.01)$, and between BAPM-total and Total ADL scores $(r=-0.37, p<0.01)$. The correlation between the BAPM scores and the functional ADL scores was not significant for the younger stroke group. Furthermore, for the relatives' ratings there was no significant relationship between BAPM-IADL and functional IADL $(r=-0.1, p>.05)$, although the BAPM-BADL had a significant correlation with MBI score $(r=-0.29, p<0.05)$, as did BAPM-Total and Total ADL functional score $(r=-0.24, p<0.05)$.

\section{Insert table 4 about here}

\section{Discussion}

This research studied the differences in self-report PM failures between older and younger people with stroke and their relatives explore the relationships between these PM failures and functional performance of stroke survivors. For the first aim of the study, we were able to differentiate the self-report PM failures of two stroke groups and with their corresponding age-similar control groups. Stroke patients' PM performance was poorer than controls which is consistent with 
previous findings on brain injury [32]. The results also indicated that the older stroke group rated their PM failure as significantly more frequent than the younger stroke group. Literature has shown similar age-related decline in PM [33-35] and greater age-related deficits in event-based PM tasks (such as those items listed in the BAPM) that demand a higher control than automatic processing [36]. Age-related decline in PM may be associated with frontal lobe function [37] and partly explained by the associated lower performance of ongoing task in the older adults [38]. To date, there are a few studies showing PM abilities are reduced in stroke patients $[22,24,39]$. The present study may be another piece of evidence that stroke patients especially the older group face more difficulties performing PM tasks in general, and IADL tasks in particular.

The second aim was to compare self-report PM failures ratings from the perspective of the patient and their relative or caregiver. There were no significant differences between ratings of patients and relatives on the BAPM except for the BAPM-IADL ratings for the old stroke group and for both groups combined. This suggests a similarity in perceptions of PM performance between patients and their caregivers, and that overall patients are accurate in rating their PM performance, at least for PM tasks related to BADL. However, caregivers rated patient's PM failure on IADL tasks as being more frequent than rated by the patients themselves in the older stroke group. This might be due to self-rating bias or diminished self-awareness. Previous research in the traumatic brain injury population has also found that patients underestimate the frequency of their PM failure compared to relatives [40]. It cannot be concluded from the current study however that under-reporting of PM problems only occurs in the older stroke group as the non-significant results for the younger stroke group may reflect the small sample size $(\mathrm{n}=5)$ of patient-relative pairs in this group.

The third aim was to investigate the relationship between PM and ADL functions. In line 
with previous findings in schizophrenia patients, it was expected that deficits of PM could possibly lead to disorganized ADL [40]. Evidence of a significant negative correlation between PM and functional ADL in schizophrenia patients has emerged in other studies [41-42]. The hypothesis that the PM of stroke patients on the BAPM would correlate with functional performance was supported. There was a medium negative relationship between PM impairment and BADL functional performance for the combined patient sample. As a larger PM score represents worse performance while larger BADL means more function independence, poor PM is found to correlate with a decline in BADL performance. Similar correlations were found for the older stroke group but not the young stroke group. This might be due to the smaller sample size.

The early findings of another study reported that PM was associated with IADL performance in an older age group [16]. PM dysfunction in both groups of stroke patients will affect their BADL and IADL performance [43]. In the present study, the relationship between PM performance and IADL performance was weaker, especially for the relative's rating where a very low correlation was found. PM failures on the IADL scale tend to relate to more non-routine PM activities than those on the BADL scale [26]. Possibly due to the non-routine and less frequent nature of these PM tasks, relatives may not have had the opportunity to observe the person with stroke performing the task or it may even be a task that the person is no longer expected to do since having their stroke (e.g., shopping, putting the garbage bin out). This could account for the weaker correlation on these items.

The findings of the present study may have several clinical implications. First, the results of the current study support that prospective memory deficits are widespread after stroke. It will be a paradigm shift from doing routine clinical practice, which traditionally focuses on training retrospective memory or memory for the past events, to pay more attention to PM training. Stroke 
patients should also be trained to execute a delayed action which may be time- (e.g. attending a medical appointment) or event-based (e.g. shopping when there is a sale). It is suggested that possible problem areas in PM can be anticipated according to age range as well as stroke. This avoids unrecognized PM difficulties that may restrict individuals' ability to engage in rehabilitation strategies, and may shed light on treatment focus and preference for remedial or compensatory activities. The treatment goal can be modified according to target PM areas perceived by patients to be a problem in everyday life as these areas may be more prevalent and demand more attention in rehabilitation. Second, family education is viewed as important as differences in perception of were observed between relatives and stroke patients, especially for items in the IADL area. Therapists should be aware of this difference in designing community skills training while seeking the understanding and support from relatives. It may also be useful to perform early screening using handy PM measures in identifying declining cognitive functions which may hamper independence in IADL, and then BADL. Thus early education, prevention and necessary interventions can be planned.

One of the limitations of this study is its cross-sectional design. This has restricted conclusions about the predictive value of PM to daily functional decline in BADL and IADL. In this small sample study, we were not able to employ an additional clinical interview or psychometric test of PM that would ensure a clinical diagnosis of PM deficit. As the BAPM is a self-report questionnaire, objectivity of findings may be questioned and a performance-based PM test may be more objective in ascertaining PM impairments in stroke patients. The Lawton IADL has a similar problem because it also uses report from patients and relatives. Nevertheless, this instrument has the benefit of asking for patients' own perceptions and those of relatives who are familiar with the patients' performance in a real-world environment to rate the performance. 
Another limitation of this study is that stroke patients may suffer from different degrees of RM impairment which was not well controlled. The possible heterogeneity across age within the two groups may also be a possible confounding variable, leading to unclear conclusions.

\section{Conclusions}

This study revealed that self-report PM ratings related to BADL and IADL skills is impaired after a stroke in patients of different age ranges. They should be routinely assessed in clinical practice for early screening and monitoring throughout rehabilitation. In addition, the findings suggest that PM impairment is more pronounced for people who experienced strokes after the age of 55 years. The relationship between PM impairment and independence in ADL performance suggests that PM impairment is an important area to target in stroke rehabilitation.

\section{Acknowledgements}

We thank The Self-help Group for the Brain Damaged and The Neighborhood Advice-Action Council in Hong Kong for assistance for data collection. We would like to express our gratitude to all participants for taking part in this study. This research was partly supported by a collaborative research fund (H-ZG66) given by The Griffith University, Australia and The Departmental Research Grant (DRG) of The Hong Kong Polytechnic University (G-YK42).

\section{Declaration of interest}


The authors report no conflicts of interest. The authors alone are responsible for the content and writing of the paper.

\section{References}

1. The altas of heart disesase and stroke: Part III, Global burden of stroke. Geneva, World Health Organization, 2014. Available online at http://www.who.int/cardiovascular_diseases/en/cvd_atlas_15_burden_stroke.pdf?ua=1, Accessed 2014 Aug 7.

2. Banks P, Pearson C. Parallel lives: Younger stroke survivors and their partners coping with crisis. Sexual and Relationship Therapy 2004; 19: 413-429.

3. Teasell RW, McRae MP, Finestone HM. Social issues in the rehabilitation of younger stroke patients. Archives of Physical Medicine and Rehabilitation 2000; 81: 205-209.

4. Daniel K, Wolfe CD, Busch MA, McKevitt C. What are the social consequences of stroke for working-aged adults? A systematic review. Stroke 2009; 40: 431-440.

5. To know about Acute Stroke. Hong Kong Stroke Society. 2014. Available online at http://www.stroke.org.hk/Acute-Stroke.html, Accessed 2014 Feb 10.

6. Varona JF, Bermejo F, Guerra JM, Molina JA. Long-term prognosis of ischemic stroke in young adults. Journal of Neurology 2004; 251: 1507-1514.

7. Hart RG, Miller VT. Cerebral infarction in young adults: A practical approach. Stroke 1983; 14: 110-114.

8. Radhakrishair K, Ashok PP, Sridharan R, Mousa ME. Stroke in the young: Incidence and pattern in Benghazi, Libya. Acta Neurologica Scandinavica 1986; 73: 434-438.

9. Morris R. The psychology of stroke in young adults: The roles of service provision and 
return to work. Stroke Research and Treatment 2011; 11: 1-10.

10. Rutten-Jacobs LCA, Maaijwee NAM, Arntz AM, Van Alebeek ME, Schaapsmeerders P, Schoonderwaldt $\mathrm{HC}$, et al. Risk factors and prognosis of young stroke. The FUTURE study: A prospective cohort study. Study rationale and protocol. BMC Neurology 2011; 11:109.

11. Varona JF, Bermejo F, Guerra JM, Molina JA. Long-term prognosis of ischemic stroke in young adults. Study of 272 cases. Journal of Neurology 2004; 251: 1507-1514

12. Putaala J, Curtze S, Hiltunen S, Tolppanen H, Kaste M, Tatlisumak T. Causes of death and predictors of 5-year mortality in young adults after first-ever ischemic stroke: the Helsinki Young Stroke Registry. Stroke 2009; 40: 2698-2703

13. Feigin VL. Stroke epidemiology in the developing world. Lancet 2005; 365: 2160-2161.

14. Roding J, Glader EL, Malm J, Eriksson M. Perceived impaired physical and cognitive functions after stroke in men and women between 18 and 55 years of age--a national survey. Disability and Rehabilitation 2009; 31: 1092-1099.

15. Fish J, Wilson BA, Manly T. The assessment and rehabilitation of prospective memory problems in people with neurological disorders: A review. Neuropsychological rehabilitation 2010; 20: 161-179.

16. Woods SP, Weinborn M, Velnoweth A, Rooney A, Bucks RS. Memory for intentions is uniquely associated with instrumental activities of daily living in healthy older adults. Journal of the International Neuropsychological Society 2012; 18: 134-138.

17. Martin M, Kliegel M, McDaniel MA. The involvement of executive functions in prospective memory performance of adults. International Journal of Psychology 2003; 38: $195-206$. 
18. Shum D, Valentine M, Cutmore T. Performance of individuals with severe long-term traumatic brain injury on time-, event-, and activity-based prospective memory tasks. Journal of Clinical and Experimental Neuropsychology 1999; 21: 49 - 58.

19. Cockburn J. Task interruption on prospective memory: A frontal lobe function? Cortex 1995; 31: 87-97.

20. Einstein GO, McDaniel MA. Normal aging and prospective memory. Journal of Experimental Psychology: Learning, Memory, and Cognition 1990; 16: 717-726.

21. Ungvari GS, Xiang YT, Tang WK, Shum D. Prospective memory and its correlates and predictors in schizophrenia: an extension of previous findings. Archives of Clinical Neuropsychology 2008; 23: 613-622.

22. Brooks BM, Rose FD, Potter J, Jayawardena S, Morling A. Assessing stroke patients' prospective memory using virtual reality. Brain Injury 2004; 18: 391-401.

23. Kim HJ, Luo L, Lim JE, Ween JE, Craik FIM. (2009). Prospective memory function in stroke patients. Journal of the Neurological Sciences 2009; 283: 319.

24. Kim HJ, Craik FI, Luo L, Ween JE. Impairments in prospective and retrospective memory following stroke. Neurocase: The Neural Basis of Cognition 2009; 15: 145-156.

25. Kvavilashvil L, Kornbrot DE, Mash V, Cockburn J, Milne A. Differential effects of age on prospective and retrospective memory tasks in young, young-old, and old-old adults. Memory 2009; 17: 180-196.

26. Man D, Fleming J, Hohaus L, Shum D. Development of a Brief Assessment of Prospective Memory (BAPM) for use with traumatic brain injury populations. Neuropsychological Rehabilitation 2011; 21: 884-898.

27. Shah S, Vanclay F, Cooper B. Improving the sensitivity of the Barthel Index for stroke 
rehabilitation. Journal of Clinical Epidemiology 1989; 42: 703-709.

28. Lawton MP, Brody EM. Assessment of older people: self-maintaining and instrumental activities of daily living. Gerontologist 1969; 9: 179-186

29. Tong AYC, Man DWK. The validation of the Hong Kong Chinese Version of the Lawton Instrumental Activities of Daily Living Scale for the Institutionalized Elderly Persons. Occupational Therapy Journal of Research 2002; 22: 132-142.

30. McDowell I, Nowell I. (1996). Measuring health: a guide to rating scales and questionnaires. New York: Oxford University Press; 1996: 56-63.

31. IBM Corp. IBM SPSS Statistics for Windows, Version 20.0 Released 2011. Armonk, NY: IBM Corp; 2011.

32. Groot YCT, Wilson BA, Evan J, Watson P. Prospective memory functioning in people with and without brain injury. Journal of the International Neuropsychological Society 2002; 8: 645-654.

33. Gao JL, Cheung RTF, Chan YS, Chu LW, Lee TMC. Increased prospective memory interference in normal and pathological aging: different roles of motor and verbal processing speed. Aging, Neuropsychology, and Cognition 2013; 20: 80-100.

34. Maylor EA. Changes in event-based prospective memory across adulthood. Aging, Neuropsychology and Cognition 1998; 5: 107-128

35. West R, Jakubeck K, Wymbs N. Age-related declines in prospective memory: behavioural and electrophysiological evidence. Neuroscience and Biobehavioral Reviews 2002; 26: 827-833.

36. Henry JD, MacLeod MS, Phillips LH, Crawford JR. A meta-analytic review of prospective memory and aging. Psychology and Aging 2004; 19: 27-39. 
37. McFarland CP, Glisky EL. Frontal lobe involvement in a task of time-based prospective memory. Neuropsychologia 2009; 47: 1660-1669.

38. Smith RE, Horn SS, Bayen UT. Prospective memory in younger and older adults: the effects of ongoing-task load. Ageing, Neuropsychology, and Cognition 2012; 19: 495-514.

39. Cheng H, Tian Y, Hu P, Wang J, Wang K. Time-based prospective memory impairment in patients with thalamic stroke. Behavioral Neuroscience 2010; 124: 152-158.

40. Roche NL, Fleming JM, Shum DK. Self-awareness of prospective memory failure in adults with traumatic brain injury. Brain Injury 2002; 16: 931-945.

41. Ritch J L, Velligan DI, Tucker D, Dicocco M, Maples NJ. Prospective memory in schizophrenia. Schizophrenia research 2003; 60: 180.

42. Twamley EW, Woods SP, Zurhellen CH, Vertinski M, Narvaez JM, Mausbach BT, et al. Neuropsychological substrates and everyday functioning implications of prospective memory impairment in schizophrenia. Schizophrenia Research 2008; 106: 42-49. doi:10.1061/j.schres.2007.10.030.

43. Spíndola L, Bruck SMD. Prospective memory in Alzheimer's disease and Mild Cognitive Impairment. Dementia e Neuropsychology 2011; 5: 64-68. 
Table I. Descriptive statistics for younger and older stroke and control groups

\begin{tabular}{|c|c|c|c|c|}
\hline & Younger stroke & Younger control & Older stroke & Older control \\
\hline Characteristics & $(n=29)$ & $(\mathrm{n}=46)$ & $(\mathrm{n}=76)$ & $(n=66)$ \\
\hline \multicolumn{5}{|l|}{ Gender } \\
\hline Male & $17(58.60 \%)$ & $15(32.60 \%)$ & $54(71.70 \%)$ & $46(69.70 \%)$ \\
\hline Female & $12(41.40 \%)$ & $31(67.40 \%)$ & $22(28.90 \%)$ & $20(30.30 \%)$ \\
\hline \multicolumn{5}{|l|}{ Age (years) } \\
\hline Mean (SD) & $49.28(5.11)$ & $45.48(3.37)$ & $67.07(6.92)$ & $68.68(5.24)$ \\
\hline Range & $36-55$ & $28-55$ & $56-94$ & $60-81$ \\
\hline \multicolumn{5}{|l|}{ Marital status } \\
\hline Single & $8(27.60 \%)$ & $32(69.56 \%)$ & $7 \quad(9.20 \%)$ & $9(13.36 \%)$ \\
\hline Married & $18(62.10 \%)$ & $14(30.44 \%)$ & $56(73.68 \%)$ & $46(69.69 \%)$ \\
\hline Divorced & $3(10.30 \%)$ & & $5(6.57 \%)$ & $6(9.09 \%)$ \\
\hline Separated & $0(\%)$ & & $2(3.98 \%)$ & $1 \quad(1.52 \%)$ \\
\hline Widowed & $0(\%)$ & & $5(6.57 \%)$ & $4 \quad(6.34 \%)$ \\
\hline \multicolumn{5}{|l|}{ Educational level } \\
\hline No formal education & $0(\%)$ & $0(\%)$ & $4(5.26 \%)$ & $1(7.57 \%)$ \\
\hline Primary school & $6(20.70 \%)$ & $13(28.26 \%)$ & $27(35.52 \%)$ & $19(30.30 \%)$ \\
\hline Secondary school & $22(75.90 \%)$ & $31(67.40 \%)$ & $42(55.28 \%)$ & $44(59.09 \%)$ \\
\hline College & $1(3.40 \%)$ & $0(0 \%)$ & $2(2.63 \%)$ & $1(1.52 \%)$ \\
\hline University or above & $0(0 \%)$ & $2(4.34 \%)$ & $1 \quad(1.31 \%)$ & $1(1.52 \%)$ \\
\hline \multicolumn{5}{|l|}{ Post stroke period } \\
\hline 1 to 3 months & $0(\%)$ & & $1 \quad(1.33 \%)$ & \\
\hline 4-6 months & $0(\%)$ & & $2(2.63 \%)$ & \\
\hline 7 to 12 months & $0(\%)$ & & $2(2.63 \%)$ & \\
\hline 1 year to 2 years & $2(6.90 \%)$ & & $4 \quad(5.26 \%)$ & \\
\hline More than 2 years & $27(93.10 \%)$ & & $67(88.15 \%)$ & \\
\hline \multicolumn{5}{|l|}{ Types of hemiplegia } \\
\hline Left side & $10(34.40 \%)$ & & $24(31.58 \%)$ & \\
\hline Right side & $19(65.50 \%)$ & & $32(68.42 \%)$ & \\
\hline \multicolumn{5}{|l|}{ History of illness } \\
\hline Heart disease & $2(6.90 \%)$ & & $3(5.93 \%)$ & \\
\hline Hypertension & $6(20.70 \%)$ & & $26(34.22 \%)$ & \\
\hline Diabetes & $2(6.90 \%)$ & & $6(7.89 \%)$ & \\
\hline Others & $12(41.40 \%)$ & & $11(14.47 \%)$ & \\
\hline Heart disease \& & $2(6.9 \%)$ & & $12(15.78 \%)$ & \\
\hline \multicolumn{5}{|l|}{ Hypertension } \\
\hline \multirow{2}{*}{\multicolumn{5}{|c|}{$\begin{array}{l}\text { Heart disease \& } \\
\text { Diabetes }\end{array}$}} \\
\hline & & & & \\
\hline Hypertension \& & $0(0 \%)$ & & $3(5.93 \%)$ & \\
\hline \multicolumn{5}{|l|}{ Diabetes } \\
\hline \multirow{2}{*}{\multicolumn{5}{|c|}{$\begin{array}{l}\text { Heart disease, } \\
\text { Hypertension \& }\end{array}$}} \\
\hline & & & & \\
\hline \multicolumn{5}{|l|}{$\begin{array}{l}\text { Period of received } \\
\text { rehabilitation service }\end{array}$} \\
\hline Less than 3 months & $5(17.20 \%)$ & & & \\
\hline 3 to 6 months & $5(17.20 \%)$ & & & \\
\hline 7 to 9 months & $6(20.70 \%)$ & & & \\
\hline 9 months or above & $13(44.80 \%)$ & & & \\
\hline
\end{tabular}




\section{Table II. Analysis of variance of stroke and control groups (young and old) on BAPM- BADL, BAPM-IADL and BADL- TOTAL}

\begin{tabular}{|c|c|c|c|c|c|}
\hline Group & & Mean & SD & $\mathrm{F}$ & $\mathrm{P}$ \\
\hline \multirow{4}{*}{ BAPM-BADL } & young stroke & 1.22 & 0.33 & \multirow[t]{4}{*}{10.57} & \multirow[t]{4}{*}{$<0.001$} \\
\hline & old stroke & 1.49 & 0.67 & & \\
\hline & young control & 1.14 & 0.14 & & \\
\hline & old control & 1.11 & 0.197 & & \\
\hline \multirow{5}{*}{ BAPM-IADL ${ }^{b}$} & young stroke & 1.45 & 0.56 & \multirow[t]{4}{*}{7.14} & \multirow[t]{4}{*}{$<0.001$} \\
\hline & old stroke & 1.60 & 0.64 & & \\
\hline & young control & 1.19 & 0.13 & & \\
\hline & old control & 1.39 & 0.30 & & \\
\hline & young stroke & 1.27 & 0.40 & \multirow[t]{4}{*}{8.75} & \multirow[t]{4}{*}{$<0.001$} \\
\hline \multirow{3}{*}{ BAPM-TOTAL ${ }^{c}$} & old stroke & 1.46 & 0.60 & & \\
\hline & young control & 1.10 & 0.11 & & \\
\hline & old control & 1.19 & 0.22 & & \\
\hline
\end{tabular}

${ }^{\text {a }}$ BAPM- BADL=the part of the Brief Assessment of Prospective Memory - relevant to basic activities of daily living.

${ }^{b}$ BAPM-IADL=the part of the Brief Assessment of Prospective Memory relevant to instrumental activities of daily living.

${ }^{c}$ BAPM-Total =the total score of the Brief Assessment of Prospective Memory 
Table III. Comparison of mean scores of patients' and relatives' ratings on BAPM-BADL, BAPM-IADL and BAPM-TOTAL

\begin{tabular}{|c|c|c|c|c|c|c|c|c|c|c|}
\hline \multirow{2}{*}{$\begin{array}{l}\text { Stroke age } \\
\text { Group }\end{array}$} & \multirow[b]{2}{*}{ Size } & \multicolumn{3}{|c|}{ BAPM-BADL $^{\mathrm{a}}$} & \multicolumn{3}{|c|}{ BAPM-IADL $^{\mathrm{b}}$} & \multicolumn{3}{|c|}{ BAPM-TOTAL $^{\mathrm{c}}$} \\
\hline & & Mean (SD) & $\mathrm{t}$ & $\mathrm{p}$ & Mean (SD) & $\mathrm{t}$ & $\mathrm{p}$ & Mean (SD) & $\mathrm{t}$ & $\mathrm{p}$ \\
\hline Younger stroke & 5 & $1.17(0.16)$ & & & $1.22(0.22)$ & & & $1.20(1.84)$ & & \\
\hline $\begin{array}{l}\text { Younger stroke's } \\
\text { relatives }\end{array}$ & 5 & $1.30(0.41)$ & -0.62 & 0.55 & $1.62(0.93)$ & -0.93 & 0.38 & $1.46(0.64)$ & -0.84 & 0.42 \\
\hline Older stroke & 60 & $1.51(0.72)$ & & & $1.88(0.74)$ & & & $1.69(0.68)$ & & \\
\hline $\begin{array}{l}\text { Older stroke's } \\
\text { relatives }\end{array}$ & 60 & $1.39(0.77)$ & 0.86 & 0.39 & $1.46(0.84)$ & 2.88 & 0.05 & $1.43(0.75)$ & 2.04 & 0.43 \\
\hline All patient & 65 & $1.38(0.74)$ & & & $1.47(0.84)$ & & & $1.43(0.74)$ & & \\
\hline All relatives & 65 & $1.48(0.69)$ & 0.78 & 0.43 & $1.83(0.73)$ & 2.56 & 0.01 & $1.66(0.67)$ & 1.83 & 0.06 \\
\hline
\end{tabular}

${ }^{\mathrm{a}} \mathrm{BAPM}-\mathrm{BADL}=$ the part of the Brief Assessment of Prospective Memory - relevant to basic activities of daily living.

${ }^{\mathrm{b}} \mathrm{BAPM}-\mathrm{IADL}=$ the part of the Brief Assessment of Prospective Memory relevant to instrumental activities of daily living.

${ }^{\mathrm{c}} \mathrm{BAPM}-\mathrm{TOTAL}=$ the total score of the Brief Assessment of Prospective Memory 
Table IV. Correlation between BAPM-BADL and functional BADL, BAPM-IALD and functional IADL and total BAPM and total ADL in patients and relatives group

\begin{tabular}{|c|c|c|c|c|}
\hline Measure & $\begin{array}{l}\text { All Patients } \\
\qquad \begin{array}{c}(n=105) \\
r\end{array}\end{array}$ & $\begin{array}{l}\text { Young Stroke } \\
\qquad \begin{array}{c}(n=29) \\
r\end{array}\end{array}$ & $\begin{array}{l}\text { Old Stroke } \\
\qquad \begin{array}{c}(n=75) \\
r\end{array}\end{array}$ & $\begin{array}{c}\text { Relatives } \\
(n=65) \\
r\end{array}$ \\
\hline $\begin{array}{c}\text { BAPM-BADL } \\
\text { MBI }^{\mathrm{b}}\end{array}$ & $-0.40 * *$ & 0.13 & $-0.48 * *$ & $-0.29 *$ \\
\hline $\begin{array}{l}\text { BAPM-IALD }^{c} \\
\text { Lawton IADL }^{d}\end{array}$ & $-0.27 * *$ & -0.23 & $-0.24 *$ & -0.10 \\
\hline $\begin{array}{l}\text { BAPM-Total }^{\mathrm{e}} \\
\text { Total ADL }^{\mathrm{f}}\end{array}$ & $-0.36 * *$ & -0.16 & $-0.37 * *$ & $-0.24 *$ \\
\hline${ }^{*} \mathrm{p}<0.05 .{ }^{* * \mathrm{p}}<0.01$ & 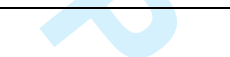 & & & \\
\hline
\end{tabular}

